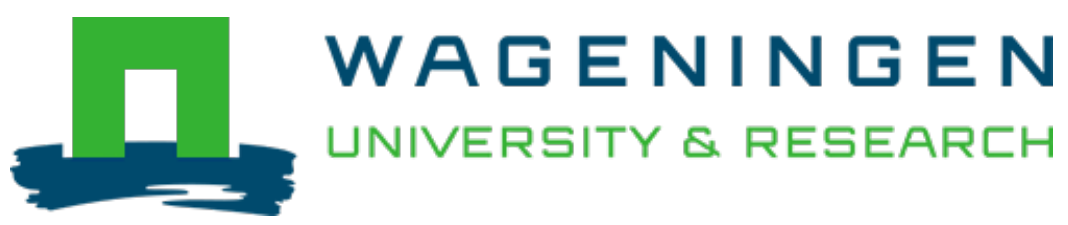

\author{
The origin and early development of wheat glutenin particles \\ Journal of Cereal Science \\ Herpen, T.W.J.M.; Cordewener, J.H.G.; Klok, H.J.; Freeman, J.; America, A.H.P. et al \\ https://doi.org/10.1016/j.jcs.2008.07.002
}

This article is made publicly available in the institutional repository of Wageningen University and Research, under the terms of article $25 \mathrm{fa}$ of the Dutch Copyright Act, also known as the Amendment Taverne. This has been done with explicit consent by the author.

Article $25 \mathrm{fa}$ states that the author of a short scientific work funded either wholly or partially by Dutch public funds is entitled to make that work publicly available for no consideration following a reasonable period of time after the work was first published, provided that clear reference is made to the source of the first publication of the work.

This publication is distributed under The Association of Universities in the Netherlands (VSNU) 'Article $25 \mathrm{fa}$

implementation' project. In this project research outputs of researchers employed by Dutch Universities that comply with the legal requirements of Article $25 \mathrm{fa}$ of the Dutch Copyright Act are distributed online and free of cost or other barriers in institutional repositories. Research outputs are distributed six months after their first online publication in the original published version and with proper attribution to the source of the original publication.

You are permitted to download and use the publication for personal purposes. All rights remain with the author(s) and / or copyright owner(s) of this work. Any use of the publication or parts of it other than authorised under article $25 \mathrm{fa}$ of the Dutch Copyright act is prohibited. Wageningen University \& Research and the author(s) of this publication shall not be held responsible or liable for any damages resulting from your (re)use of this publication.

For questions regarding the public availability of this article please contact openscience.library@wur.nl 


\title{
The origin and early development of wheat glutenin particles
}

\author{
T.W.J.M. van Herpen ${ }^{\text {a, } *}$, J.H.G. Cordewener ${ }^{\text {a }}$, H.J. Klok ${ }^{\text {b }}$, J. Freeman ${ }^{c}$, A.H.P. America ${ }^{\text {a }}$, D. Bosch ${ }^{\text {a }}$, \\ M.J.M. Smulders ${ }^{\text {a, }}$ L.J.W.J. Gilissen ${ }^{\text {a }}$, P.R. Shewry ${ }^{c}$, R.J. Hamer ${ }^{\text {d,e }}$ \\ ${ }^{a}$ Plant Research International, Wageningen UR, P.O. Box 16, NL-6700 AA Wageningen, The Netherlands \\ ${ }^{\mathrm{b}}$ NIZO Food Research BV, P.O. Box 20, NL-6710 BA Ede, The Netherlands \\ ${ }^{\mathrm{c}}$ Rothamsted Research, Harpenden, Hertfordshire AL5 2JQ UK \\ d Laboratory for Food Chemistry, Wageningen University, Bomenweg 2, NL-6700 EV Wageningen, The Netherlands \\ ${ }^{\mathrm{e}}$ TI Food E' Nutrition, P.O. Box 557, NL-6700 AN Wageningen, The Netherlands
}

\section{A R T I C L E I N F O}

\section{Article history:}

Received 10 December 2007

Received in revised form 5 June 2008

Accepted 7 July 2008

\section{Keywords:}

GMP

Protein bodies

Wheat

Origin

\begin{abstract}
A B S T R A C T
Breadmaking quality is strongly related to the glutenin macropolymer (GMP) fraction. Don and coworkers [Don, C., Lichtendonk, W.J., Plijter, J.J., Hamer, R.J., 2003a. Glutenin macropolymer: a gel formed by particles. Journal of Cereal Science 37, 1-7] showed that GMP consists of spherical glutenin particles and suggested that these originate from the protein bodies (PBs) observed in developing grain. We have tested this hypothesis by systematically comparing SDS-soluble and SDS-insoluble protein fractions from both PBs and flour. These preparations were analysed at the molecular, oligomer, particle and microscopic levels. Comparison of PBs isolated from immature seeds with glutenin particles isolated from mature seeds revealed strong similarities in protein composition and the presence of large glutenin oligomers. However, the glutenin particles from mature wheat were significantly larger than PBs. We suggest that PBs are the building blocks for the formation of much larger glutenin particles which are formed during the desiccation phase of kernel development.
\end{abstract}

(c) 2008 Elsevier Ltd. All rights reserved.

\section{Introduction}

Gluten polymers from wheat are among the largest and most complex protein networks in nature with MWs of more than 10 million (Wieser, 2007). The differences in breadmaking quality between flours of different wheat varieties also parallel differences in a gluten protein fraction called glutenin macropolymer (GMP) (Graveland, 1984; Graveland et al., 1982; Weegels et al., 1996, 1997). GMP is the glutenin fraction which is insoluble in various solvents (SDS or acetic acid) (Weegels et al., 1996, 1997) and consists of spherical glutenin particles (Don et al., 2003). These glutenin particles also vary in size, and this variation correlates with a key technological quality parameter: dough mixing properties (Don et al., 2005). The genetic background and growing conditions also affect the quality of GMP, the glutenin particle size and, consequently, flour quality, but the mechanism behind this effect is not

Abbreviations: CSLM, confocal laser scanning microscopy; DAF, days after flowering; ER, endoplasmic reticulum; FITC, fluorescent protein label; FPLC, fast protein liquid chromatography; GMP, glutenin macropolymer; HMW, high molecular weight; HPLC, high performance liquid chromatography; LMW, low molecular weight; PAGE, polyacrylamide gel electrophoresis; PBs, protein bodies; SDS, sodium dodecyl sulphate; SE, size exclusion.

* Corresponding author. Tel.: +31 317477164; fax: +31 317418094.

E-mail address: teun.vanherpen@wur.nl (T.W.J.M. van Herpen). known (Don et al., 2005). However, Don and co-workers (2003) suggested that the glutenin particles in GMP are related in origin to the PBs observed in developing wheat endosperm.

The wheat gluten proteins can be classified into three groups on the basis of their structural and evolutionary relationships. These are sulphur-rich (S-rich), sulphur-poor (S-poor) and high molecular weight (HMW) groups, with a number of subgroups within the Srich and S-poor groups. However, this classification does not correspond directly to the polymeric and monomeric fractions in the wheat kernel (glutenins and gliadins, respectively) (Köhler et al., 1993), with the HMW subunits and the S-rich LMW subunits being the main contributors to glutenin particles.

Wheat seed storage proteins are synthesised in developing grain and are initially deposited in discrete protein bodies (PBs) (Shewry and Halford, 2002). All gluten proteins are initially synthesised on the rough ER and co-translationally translocated into the lumen. However, it appears that some components, probably mainly gliadins, are transported via the Golgi to the protein storage vacuole whereas others, probably mainly glutenins, are deposited within the lumen of the ER to form a second population of ER-derived protein bodies (Kim et al., 1988; Rubin et al., 1992). It has also been suggested that these ER-derived protein bodies are subsequently absorbed by protein storage vacuoles in a process analogous to autophagy (Galili, 1997; Shewry, 1999; Shewry and Halford, 2002). This leads to the formation of an apparently continuous gluten 
protein matrix in the cells of the mature grain (Parker, 1980). The PBs in developing grains also contain dark-staining inclusions of the globulin storage protein triticin (Bechtel et al., 1991).

The accumulation of wheat seed storage protein commences as early as seven days after flowering (DAF) and ends at the beginning of the desiccation phase. In contrast, a close correlation was found between the accumulation of the GMP and the rapid loss of water during desiccation (Carceller and Aussenac, 1999, 2001). The percentage of SDS-insoluble polymers as a proportion of total polymers can increase from less than $10 \%$ at the end of kernel ripening to $50 \%$ in as little as 10 days, although the synthesis of gluten proteins is completed before this occurs (Carceller and Aussenac, 1999). Since glutenin insolubility is related to aggregate size, this indicates a lower degree of aggregation within PBs from immature wheat grain compared to within the gluten matrix of the mature wheat grain.

It has been recently suggested that the glutenin particles isolated from mature wheat flour and observed as spherical shaped particles using confocal laser scanning microscopy (CLSM) originate from the individual PBs as observed in immature wheat endosperm (Don et al., 2003). If this is true, the PBs and glutenin particles should exhibit similarities at different levels: subunit composition, polymer composition, polymer size and polymer network properties.

In this study we have tested this hypothesis by comparing PBs from immature wheat with flour from mature grain of the same variety. The preparations from mature and immature grains were also compared for their ability to form a physical gel and for their composition of protein subunits and oligomers. Finally, their particle sizes were determined by laser diffraction and CLSM was used to study their compositions using specific stains for protein and free sulfhydryl groups.

Our results support the hypothesis that glutenin particles originate from the PBs. Additionally we suggest that further aggregation of individual PBs is required to generate the large particles observed in GMP.

\section{Experimental}

Wheat material used for protein body isolation was Triticum aestivum cv Cadenza of approximately 15 DAF (grown under controlled environment conditions at Rothamsted Research, Harpenden, UK). Flour was obtained by grinding mature dry grains from the same cultivar grown under the same conditions with an A11 Basic IKA Analytical Mill (IKA-WERKE GmbH \& Co KG).

\subsection{Protein body and protein body gel isolation}

Endosperms were removed from all of the individual developing grain from 10 complete immature wheat spikes of $T$. aestivum $\mathrm{cV}$ Cadenza at approximately 15 DAF and chopped with a razor blade in $20 \mathrm{ml}$ buffer 1 (20 mM, HEPES, pH7.6, $100 \mathrm{mM}$ NaOAc, $5 \mathrm{mM}$ $\mathrm{MgCl}_{2}$ ). The homogenate was filtered through four layers of cheese cloth, pre-wetted with buffer 1 . The residue was washed with $10 \mathrm{ml}$ buffer 1 and the filtered homogenate was layered on top of a $1.75 \mathrm{M}$ sucrose cushion in buffer 1 and centrifuged at $500 \mathrm{~g}$ for $2 \mathrm{~min}$ at $10{ }^{\circ} \mathrm{C}$. The material from the top of the cushion was collected and resuspended in $20 \mathrm{mM}$ HEPES, pH7.6, $100 \mathrm{mM}$ NaOAc, $5 \mathrm{mM}$ EDTA, and $0.25 \mathrm{M}$ sucrose, to a total volume of $10 \mathrm{ml}$. A two-step Percoll density gradient was prepared: a $1.13 \mathrm{~g} / \mathrm{ml}$ and a $1.08 \mathrm{~g} / \mathrm{ml}$. The suspension was layered onto the two-step Percoll gradients and centrifuged at $7100 \mathrm{~g}$ at $10{ }^{\circ} \mathrm{C}$ for $60 \mathrm{~min}$. The PBs were collected in $0.5 \mathrm{ml}$ volume from the surface of the $1.13 \mathrm{~g} / \mathrm{ml}$ Percoll layer. The same volume of demineralised water was added to the PBs and the mixture vortexed briefly and then centrifuged for $2 \mathrm{~min}$ at $16,000 \mathrm{~g}$. The supernatant was removed and the pellet was resuspended in a total of $1 \mathrm{ml}$ water. This was vortexed and centrifuged as before. Finally, the PB pellet was resuspended in an appropriate volume of demineralised water for immediate use. Further details are provided elsewhere (Davy et al., 2000).

SDS-insoluble protein was isolated by dissolving the PB pellet in $1.5 \%(\mathrm{w} / \mathrm{v})$ SDS and centrifugation for $10 \mathrm{~min}$ at $16,000 \mathrm{~g}$ at room temperature. The supernatant containing SDS-soluble proteins was decanted and kept for later analysis while the SDS-insoluble protein was recovered as a gel (PB-gel).

\subsection{Isolation of SDS-insoluble (GMP) and SDS-soluble wheat protein from mature grain}

$0.5 \mathrm{~g}$ Flour of cv Cadenza was dissolved in $10 \mathrm{ml}$ 1.5\% (w/v) SDS. Ultracentrifugation was performed at $78,000 \mathrm{~g}$ at $20^{\circ} \mathrm{C}$ for $30 \mathrm{~min}$ (Centrikon T-2060, Kontron Instruments, USA). After ultracentrifugation, GMP was observed as a gel on top of a starch layer. The supernatant containing SDS-soluble protein was decanted and retained while the gel layer (GMP) was collected.

\subsection{SE-HPLC analysis of SDS-soluble proteins (profible method)}

Three replicates of $10 \mathrm{mg}$ of PB pellet and $0.8 \mathrm{mg}$ of flour were suspended in $1 \mathrm{ml} 1 \%(\mathrm{w} / \mathrm{v})$ SDS, $0.1 \mathrm{M}$ sodium phosphate buffer (pH 6.9). Controlled ultrasonication with a sonicator (Vibra Cell 72434, Bioblock, Illkirch, France) delivering ultrasonic vibrations at $20 \mathrm{kHz}$ and equipped with a $3 \mathrm{~mm}$ diameter tip probe was performed for 2 min without interruption (no overheating was observed), prior to separation by size-exclusion HPLC using a TSKgel G $4000 \mathrm{SW}$ column $(7.5 \mathrm{~mm} \times 30 \mathrm{~cm}$ resolving column, Sigma Cat. No. 805790 and a $7.5 \mathrm{~mm} \times 7.5 \mathrm{~cm}$ guard column, Sigma Cat. No. 805371). Further details are provided elsewhere (Dachkevitch and Autran, 1989; Millar, 2003; Morel et al., 2000).

\subsection{SE-FPLC chromatography of SDS-soluble proteins}

Size-exclusion FPLC was performed using a Superose 6 HR 10/30 column (GE Healthcare, UK) pre-equilibrated with $1 \%(\mathrm{w} / \mathrm{v})$ SDS in $0.1 \mathrm{M}$ sodium phosphate buffer $(\mathrm{pH} 7)$. Three replicates of aliquots $(0.1 \mathrm{ml})$ of SDS-soluble protein from flour and from PBs were loaded on the column without prior sonication and fractionated using a flow rate of $0.3 \mathrm{ml} / \mathrm{min}$. Eluate fractions of $0.5 \mathrm{ml}$ were collected for SDS-PAGE analysis. The elution pattern was monitored at $280 \mathrm{~nm}$.

\subsection{SDS-PAGE gel electrophoresis}

Fractions from SE-FPLC were analysed on a Multiphor II horizontal SDS electrophoresis system using ExcelGel SDS gradient 818 gels (GE Healthcare, UK). Proteins were precipitated using $10 \%$ $(\mathrm{w} / \mathrm{v})$ trichloroacetic acid (TCA) and after washing with ice-cold acetone, the air dried pellets were dissolved in sample buffer $(2 \%$ (w/v) SDS, $62.5 \mathrm{mM}$ Tris-HCl pH 6.2, 10\% (w/v) glycerol, $0.01 \mathrm{mg} / \mathrm{ml}$ bromophenol blue) with and without $100 \mathrm{mM}$ DTT as a reducing agent. Proteins were visualized using silver staining (Rabilloud et al., 1988). Protein body gel and fresh GMP fractions were also analysed on an ExcelGel SDS gradient 8-18 (GE Healthcare, UK) without prior precipitation.

\subsection{Protein identification using nano-liquid chromatography - mass spectrometry}

The bands of interest were excised from the SDS-PAGE gel and sliced into $1 \mathrm{~mm}^{3}$ pieces. Gel pieces were processed essentially according to Shevchenko et al. (1996). Tryptic digests were then analysed by one-dimensional LC-MS using an Ettan ${ }^{\mathrm{TM}}$ MDLC system 
(GE Healthcare, UK) in a high-throughput configuration directly connected to a Q-TOF-2 mass spectrometer (Waters Corporation, Manchester, UK). Samples ( $5 \mu \mathrm{l})$ were loaded on $5 \mathrm{~mm} \times 300 \mu \mathrm{m}$ ID Zorbax $^{\text {TM }} 300$ SB C18 trap columns (Agilent Technologies, USA), and the peptides were separated on a $15 \mathrm{~cm} \times 100 \mu \mathrm{m}$ ID Chromolith CapRod monolithic C18 capillary column at a flow rate of approximately $1 \mu \mathrm{l} / \mathrm{min}$. Solvent A contained an aqueous $0.1 \%$ FA solution and solvent B contained $84 \% \mathrm{ACN}$ in $0.1 \% \mathrm{FA}$. The gradient consisted of $5 \%$ B for $10 \mathrm{~min}$, a linear gradient to $30 \%$ B over $40 \mathrm{~min}$, a linear gradient to $100 \%$ B over $10 \mathrm{~min}$, and then a linear gradient back to $5 \%$ B over 5 min.

MS analyses were performed in positive mode using ESI with a NanoLockSpray source. As lock mass, [Glu ${ }^{1}$ ]fibrinopeptide B ( $1 \mathrm{pmol} / \mu \mathrm{l}$ ) (Sigma, USA) was delivered from a syringe pump (Harvard Apparatus, USA) to the reference sprayer of the NanoLockSpray source at a flow rate of $1 \mu \mathrm{l} / \mathrm{min}$. The lock mass channel was sampled every $10 \mathrm{~s}$. Data dependent acquisition (DDA) was performed with the Q-TOF-2 operating in MS/MS mode. MS/MS data collected during a LC-MS/MS run were submitted to database search using the Protein Lynx Global Server V2.2.5 (Waters Corporation, USA), taking fixed (carbamidomethyl) and variable (oxidation of methionine) modifications into account. MS/MS spectra that led to no identification in the NCBI non-redundant protein database, were compared to translated wheat triticin EST sequences obtained from the NCBI database.

\subsection{Particle size distribution}

Freshly prepared wet GMP from flour was dispersed in $1.5 \%(\mathrm{w} /$ v) SDS (10 ml) by rotating overnight. The PB-gel was also dispersed in $1.5 \%(\mathrm{w} / \mathrm{v})$ SDS $(2 \mathrm{ml})$ by rotating overnight. Intact PBs were dispersed in water and used directly. Particle size distributions were measured using a Mastersizer 2000 (Malvern Instruments, UK). The laser diffraction pattern obtained with the instrument can be transformed into particle size distribution using the Fraunhofer theory assuming a spherical particle shape. The range of the instrument is $0.02-2000 \mu \mathrm{m}$. Dispersions were transferred to the suspension water in the sample vessel. The obscuration signal for diffraction was approximately $10 \%$. For each sample, three replicates were performed. Data were exported to Excel to perform calculations as described by Don et al. (2005a) and Wang et al. (2005).

\subsection{Confocal scanning laser microscopy (CLSM)}

Freshly prepared wet GMP from flour was dispersed in $1.5 \%$ (w/ v) SDS $(10 \mathrm{ml})$ by rotating overnight. Protein body gel was also dispersed in $1.5 \%(\mathrm{w} / \mathrm{v})$ SDS $(2 \mathrm{ml})$. Intact PBs were dispersed in water and used directly. Samples were stained for protein with FITC (a fluorescent label, specific for proteins) and with Nile Red for hydrophobic molecules. Free $\mathrm{SH}$ groups were stained with the fluorescent marker Alexa Fluor 568 C5 maleimide (Invitrogen, USA, Cat. No. A20341). In addition, the protein bodies were extracted with a detergent (in this case $0.02 \%(w / v)$ SDS or $1 \%(v / v)$ Triton X100) after labelling with FITC and Alexa Fluor 568. Samples were observed using a Leica TCS NT confocal laser scanning microscope (model Leica DM IRBE). Two replicates of the different treatments were analysed and gave similar results.

\section{Results}

Breadmaking quality relates to the capacity of GMP formation which consists of spherical glutenin particles (Don et al., 2005). It was further suggested that these glutenin particles originate from PBs. We have tested this hypothesis by systematically comparing the properties and compositions of PBs from developing grain and GMP from flour.

GMP was isolated from mature wheat (cv Cadenza) flour using detergent solution (1.5\% (w/v) SDS) and ultracentrifugation while PBs were isolated from immature (15 DAF) grains of the same wheat variety and purified using Percoll density gradient centrifugation. Extraction of the protein body preparation with SDS followed by centrifugation led to the formation of a gel which had a similar appearance to the GMP gel isolated from mature wheat (Fig. 1). SDS emulsified the lipid membrane surrounding the protein body but left discrete bodies. Wellner et al. (2005) performed a similar experiment using chloroform/methanol to remove the lipid membrane but in contrast, this resulted in the fusion of the contents to form a cohesive, elastic protein mass.

\subsection{SDS-soluble proteins in PB from developing grain and in flour from mature grain}

The ability to form a SDS-insoluble gel indicates the presence of polymers in the PB and GMP samples. More information about proteins in these preparations was obtained using SE-HPLC. This method uses sonication to shear large polymers and render them soluble. Consequently, although the profiles are reproducible and relate to quality parameters, they do not represent the precise molecular mass distributions of the unextracted polymers. The three replicates of the same sample gave similar results. The separation profiles obtained using the SDS-soluble proteins in PBs from developing grain (Fig. 2A) and the SDS-soluble proteins in flour from mature grain (Fig. 2B) were essentially similar. Five fractions could be distinguished, which represent HMW glutenin polymers (F1), LMW glutenin polymers (F2), gliadins (F3 and F4) and albumins and globulins (F5), respectively. Apart from differences relating to the amount of protein applied to the column, the profile obtained with the protein body sample is similar to the mature wheat grain sample except that the proportion of the F4 fraction is lower for the protein body proteins. This indicates that the PB sample contains relatively less monomeric gliadin proteins and suggests that it is enriched in protein bodies derived from the ER which are enriched in glutenins (Kim et al., 1988; Rubin et al., 1992). In contrast, the GMP fraction from flour corresponds to the matrix proteins which comprise both ER and vacuolar-derived PBs.

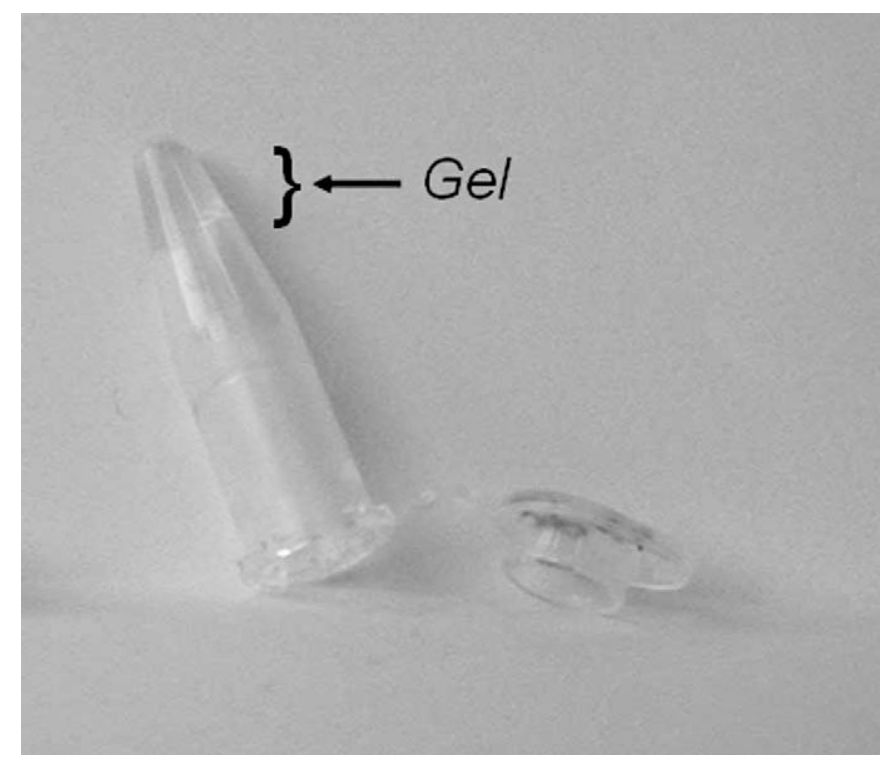

Fig. 1. The SDS-insoluble protein from protein bodies forms a gel-like pellet after centrifugation. 


\section{A Protein body}

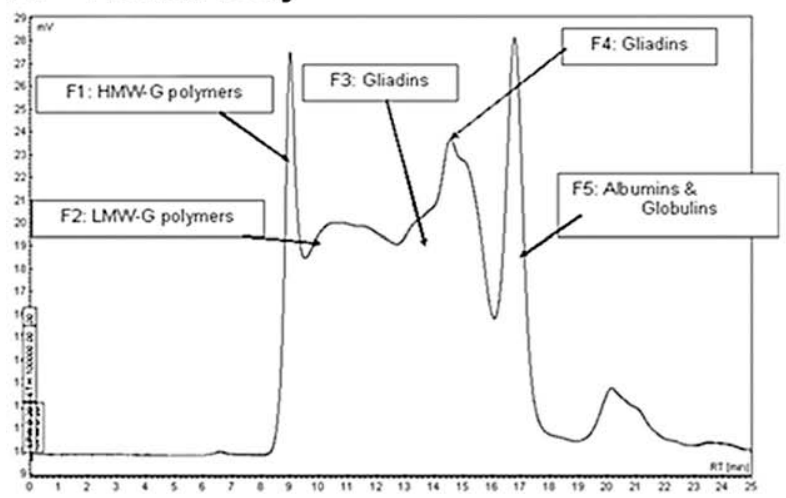

\section{B Mature wheat}

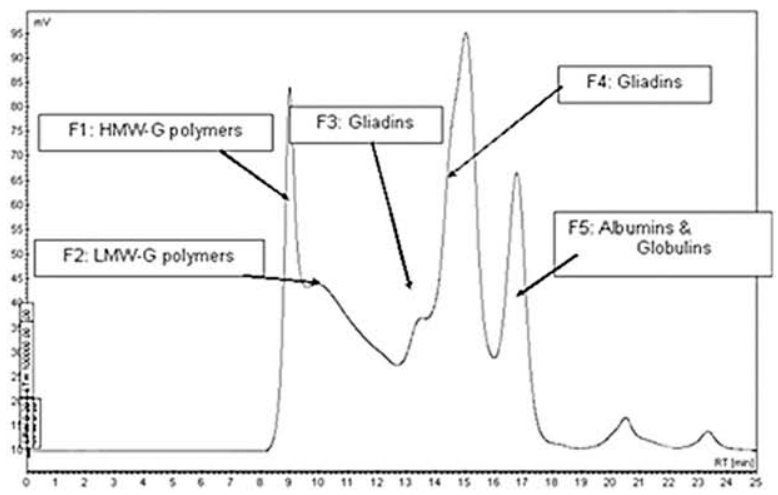

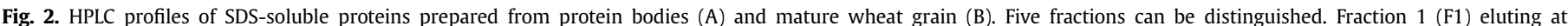

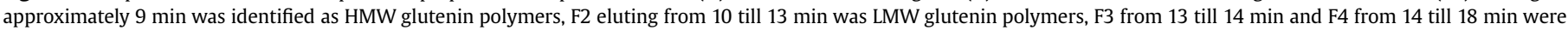

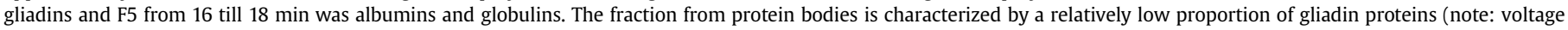
range $(\mathrm{mV})$ is 3 times lower in protein body sample).

\subsection{Composition of SDS-soluble polymeric and SDS-insoluble gel fractions}

The polymeric and oligomeric glutenin fractions (F1 and F2) would be expected to contribute mainly to gel formation observed in both PB and GMP. These fractions were therefore analysed in more detail with respect to their protein composition. SE-FPLC was used to prepare comparable fractions as obtained with SE-HPLC (Fig. 2). Three replicates of the F1 and F2 fractions were analysed with SDS-PAGE under reducing and non-reducing conditions. The three replicates gave similar results. Under non-reducing conditions a smear was visible in all lanes, whereby fractions eluting later from the size-exclusion column showed the highest mobility in the gel (Fig. 3A, 3C). The reduced fractions (Fig. 3B and D) show the presence of both HMW glutenin subunits (between 150 and $75 \mathrm{kD}$ ) and LMW glutenin subunits/gliadins. A typical difference between the protein patterns of the SDS-soluble preparations from mature and immature grain is the presence in the latter of some low molecular weight bands at approximately $20 \mathrm{kD}$. This agrees with Wellner et al. (2005) who also observed comparable low molecular weight bands in the PB preparations but not in the sample prepared from wheat flour.

To compare the proteins present in the SDS-insoluble gel fractions from mature and immature grain, SDS-insoluble gel was boiled in SDS sample buffer in the presence and absence of the reducing agent, DTT. Under non-reducing conditions the solubilised polymers were not able to enter the gel except for a small fraction of the gel from immature grain, indicating that at least some of the polymeric components in immature grain were smaller than those in mature grain. However, the two SDS-insoluble fractions show similar patterns of subunits to the SDS-soluble polymers after reduction. It is of interest that the protein band of approximately
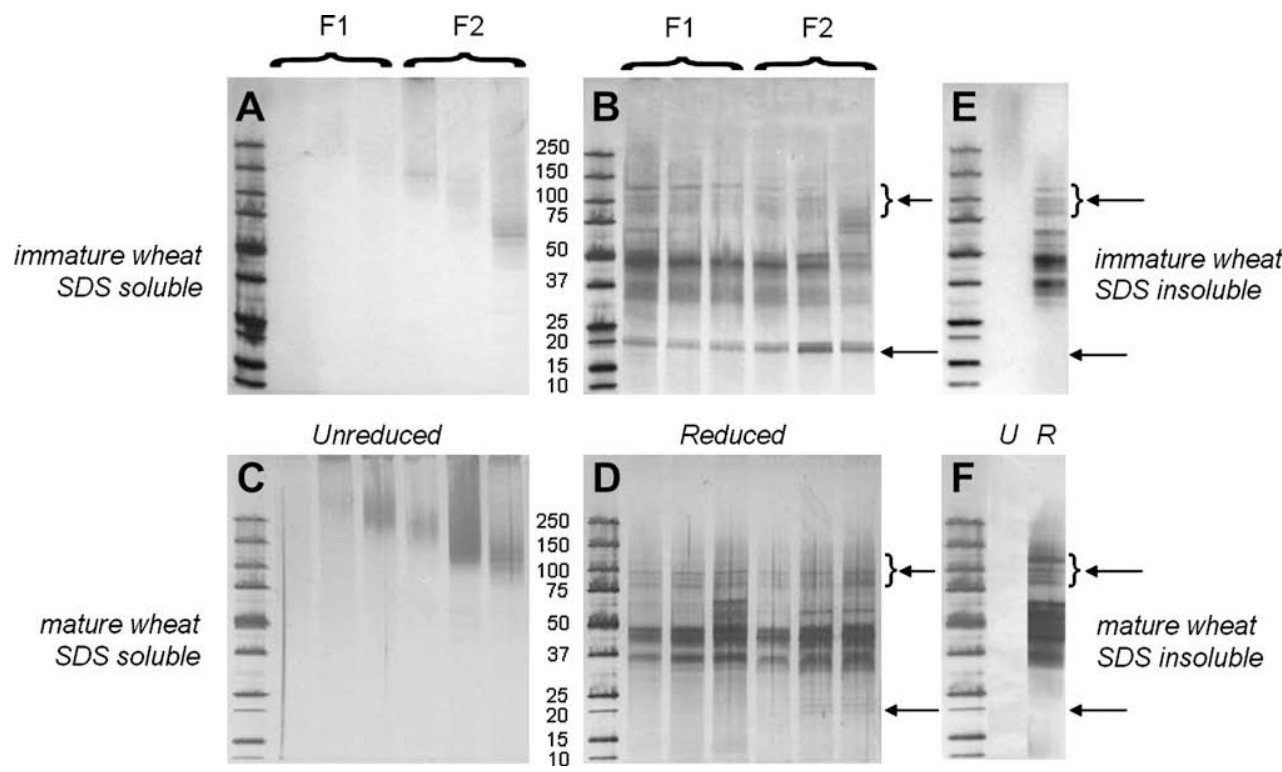

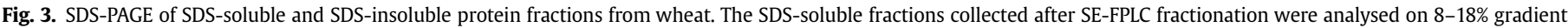

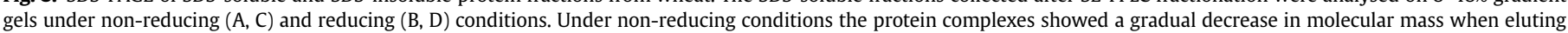

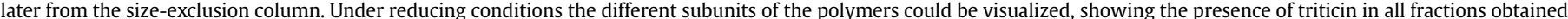

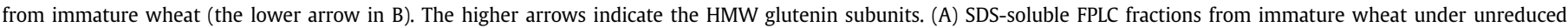

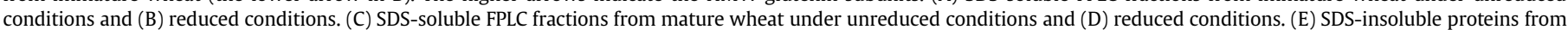

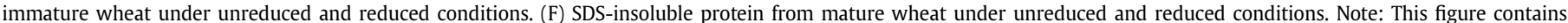
different gels from different experiments which were electronically combined in one figure. 
$20 \mathrm{kD}$ was not observed in the gel fractions from either the immature (Fig. 3E) or the mature (Fig. 3F) samples.

\subsection{Identification of triticin in the SDS-soluble fraction of PBs of immature wheat}

Three protein bands at an estimated molecular mass of $20 \mathrm{kD}$ in the SDS-PAGE gel (indicated by an arrow in Fig. 3B) were cut out of the gel and, after tryptic digestion, analysed by LC-MS/MS. All three bands were identified as the small basic subunit of triticin, yielding between 8 and 11 peptides that could be assigned to the EST sequence CJ634623 (Fig. 4). In addition to pure tryptic peptides (tryptic recognition at $\mathrm{K} / \mathrm{R}-\mathrm{X}$, with $\mathrm{X}$ is not $\mathrm{P}$ ), two half tryptic peptides were detected due to aspecific cleavage, i.e. VHLYQNAIISPLWNINAH ... and ... VIANAYGISR. Furthermore, apart from the N-terminal peptide GLEENFCDHK, a truncated form was observed missing the first two amino acids $G$ and $L$. As no clear differences in peptide composition of the tryptic digests of the three individual bands were found, the reason for the differences in mobility on SDS-PAGE could not be explained by differences in amino acid sequence. Overall we found a sequence coverage of $67 \%$ (131 out of 195 amino acids) of the predicted EST protein sequence (Fig. 4).

\subsection{Morphological appearance of the PBs and the effect of SDS}

The PB preparations were analysed by CLSM microscopy, using specific fluorescent labels for protein, hydrophobic groups and free sulfhydryl groups. In addition, the labelled PBs were extracted with a detergent to observe effects on protein solubility and free $\mathrm{SH}$ groups under conditions similar to those used for GMP extraction. Each treatment was performed twice and similar results were obtained.

Double staining to show protein and protein hydrophobic groups (Fig. 5A) revealed filled spheres with a size around $10 \mu \mathrm{m}$. The protein spheres were accompanied by inclusion bodies which stained with Nile Red indicating hydrophobic properties. Double staining for protein and free SH groups (Fig. 5D) showed the presence of free $\mathrm{SH}$ groups throughout the protein body. The hydrophobic inclusion bodies were rapidly dissolved when the preparations were treated with SDS, either by passive diffusion (Fig. 5B) or with shaking to form an emulsion (Fig. 5C). This occurred within a few seconds and could be observed in real time under the CLSM microscope (supplementary data). After staining for protein and hydrophobic groups, SDS was added and the samples were shaken (inputting energy), resulting in dispersion (Fig. 5C). Similar results were obtained when Triton X-100 was used instead of SDS, and indicates that the PBs observed in Fig. 5B are stabilised mainly by non-covalent interactions. The same procedure was applied to PBs which were stained for free SH groups before adding SDS and shaking (Fig. 5E). In this case particles that were stable in a SDS solution were observed, and these appeared to consist of aggregates of several individual PBs.

\section{GLEENFCDHK/LSVN I DDPSR/ADIYNPR/AGTITR/LNSQTF P I LN IVQMSATR/VHLYQNA I I SPLWN I NAHSVMYMI QGH I WV QVVNDHGR /NVFNDL LSPGQLL I I PQNYVVL K / K / AQR / DGSK /YIEFK/TNANSMVSHI AGK/NSI LGALPVDVIANAYGISR/T $\mathrm{EAR} / \mathrm{SLK} / \mathrm{FSR} / \mathrm{EEELGVFAPK} / \mathrm{FSQSIFR} / \mathrm{SFPNGEEESS}$}

Fig. 4. Tryptic peptides of wheat triticin identified by LC-MS/MS. After tryptic digestion of the $20 \mathrm{kDa}$ protein bands indicated in Fig. 3, the resulting peptides were fractionated by nano-LC and on-line sequenced by Q-TOF MS/MS. The amino acid sequences given in bold were observed in the tryptic digests, and covered $67 \%$ of the predicted protein sequence of the wheat EST, CJ634623.

\subsection{Size distribution of the PBs and GMP particles}

The particle size distribution of the protein bodies observed by CLSM was determined using laser diffraction with three replicates for each treatment (Fig. 6). This showed that the weighted mean diameter $(D)[4,3]$ of the untreated preparations was $11.7 \pm 2.0 \mu \mathrm{m}$, while the value for the insoluble fraction isolated from protein bodies (Protein body gel) was $12.3 \pm 0.2 \mu \mathrm{m}$. In contrast, the particle size of GMP from mature seeds was consistently larger with a volume weighted mean of $76.5 \pm 2.2 \mu \mathrm{m}$. This size difference with GMP from mature seeds being larger than PB and PB-gel from immature wheat is in agreement with the results described in Section 3.4 and shown in Fig. 3E and F. The particle size distributions of the PB and PB-gel preparations show almost perfect Gaussian distributions while the GMP preparation from mature seeds shows the presence of fractions of smaller sizes than the main peak. If all of the particles are considered as spheres (as suggested by the CLSM analysis), the average volume of a protein body can be calculated as $0.839 \times 10^{-9} \mathrm{ml}$, of a glutenin particle from PBs as $0.972 \times 10^{-9} \mathrm{ml}$ and of a glutenin particle from mature endosperm as $0.234 \times 10^{-6} \mathrm{ml}$. Thus, the average volumes of glutenin particles from immature wheat and dry wheat grain differ by a factor of 241 .

\section{Discussion}

Differences in breadmaking quality parallel differences in the GMP fraction, which consists of spherical glutenin particles whose size correlates with a key functional parameter: dough mixing properties (Don et al., 2005). It has also been suggested that there is a developmental relationship between the protein bodies deposited in developing grain and the GMP particles prepared from mature grain (Don et al., 2003). Such a relationship may also offer an explanation for the established effects of environmental and genetic factors on GMP properties and processing quality (Don et al., 2005).

A systematic comparison between PBs isolated from immature wheat seeds and GMP isolated from mature seeds revealed strong similarities in protein composition including the presence of large glutenin oligomers. Both preparations also gave an SDS-insoluble gel protein fraction. However, the proportion of protein that was insoluble in SDS was much greater in the GMP than in the PBs, as shown previously by Carceller and Aussenac (1999, 2001). There were also large (more than 200-fold) differences in the sizes of the particles present in the SDS-insoluble protein from mature wheat as compared to immature wheat despite the fact that their subunit compositions were similar as demonstrated by SDS-PAGE after reduction. These results indicate that the SDS-insoluble networks in immature and in mature wheat kernels consist of the same subunits, but that they differ in their degree of polymerisation. The SDS-soluble glutenin polymers (F1 and F2), from immature and mature wheat also had similar subunit compositions to the SDSinsoluble fractions, except that triticin was present in a polymeric state in the SDS-soluble polymers of immature wheat, but not in the SDS-insoluble fractions of mature or immature grains.

\subsection{Triticin}

Triticin is related to the 11S storage globulins present in many seeds and has been suggested to affect the breadmaking properties of wheat (Sievert et al., 1991; Singh et al., 1993). Two subunits of triticin, the larger acidic subunit and the smaller basic subunit, are coded by a single gene and are produced by post-transcriptional cleavage of a single protriticin (Singh et al., 1993). Singh and Shepherd (1985) showed that triticin forms tetrameric oligomers that consist of two acidic subunits of 52 and $58 \mathrm{kDa}$, and two basic subunits of 22 and $23 \mathrm{kDa}$ as observed after reduction of the 

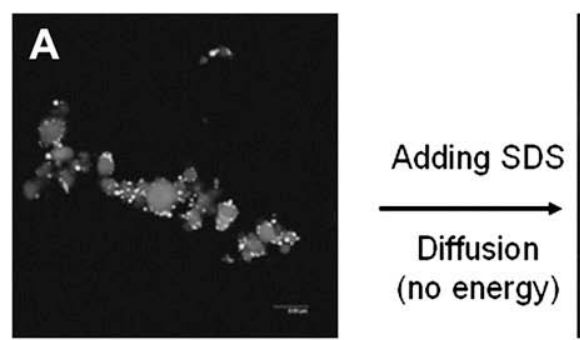

Staining: hydrophobic + protein
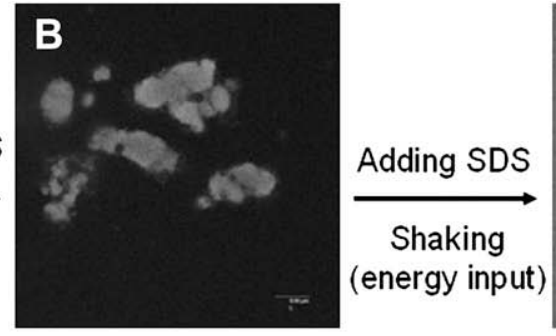

Staining: hydrophobic + protein

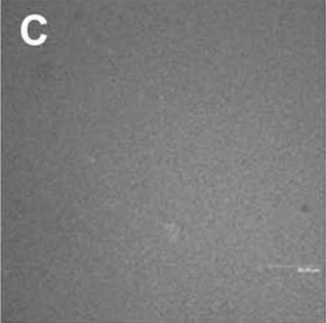

Staining: hydrophobic + protein

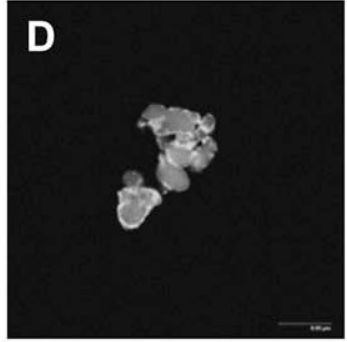

Staining: free $S H+$ protein

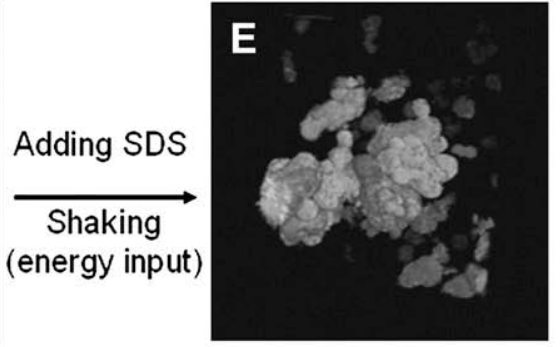

Staining: free $S H$

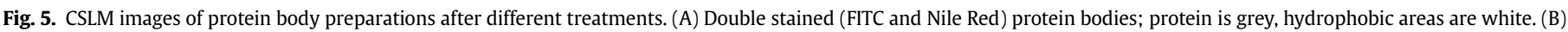

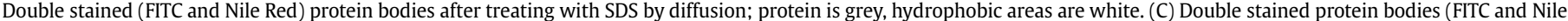

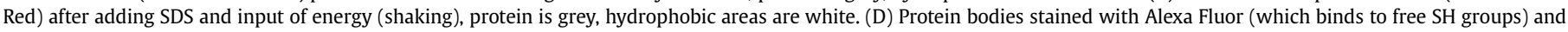

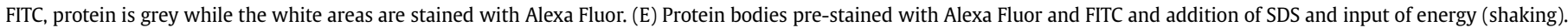

disulphide bonds. Triticin has free SH groups in its structure which allow it to polymerise (Singh et al., 1991), however the basic subunit contains only one cysteine residue. We identified three bands of approximately $20 \mathrm{kDa}$ as the basic subunit of triticin. These bands were found in the SDS-soluble protein fractions. The absence of the $20 \mathrm{kDa}$ bands in the SDS-insoluble fractions suggests a function of triticin in the degree of solubilization/polymerization. In the SDS-soluble fraction of mature wheat, only a faint band was visible at the expected mass of the basic triticin subunit. This corresponds to the results of Singh and Shepherd (1987) who showed that triticin protein accumulation occurs mainly between 10 and 21 DAF with no significant increase in accumulation beyond 21 DAF. In our analysis the basic subunit and not the acidic subunit of triticin was identified. One reason for this is that the $20 \mathrm{kDa}$ basic subunit was well separated from the other proteins in the gel, while in the mass range where we can expect the acidic subunit (around

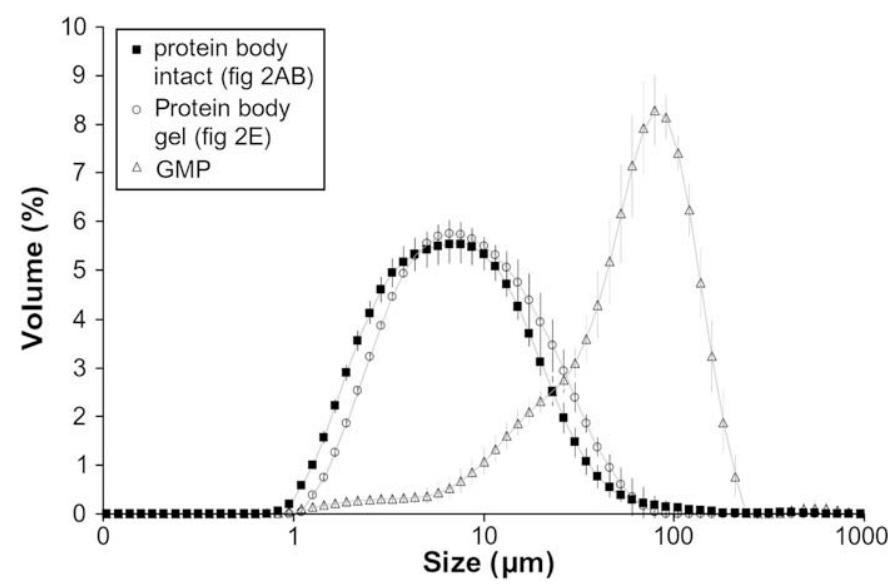

Fig. 6. Volume percentage distributions of protein bodies and gel protein fractions Intact protein bodies are shown as squares, SDS-insoluble gel protein from isolated protein bodies as circles and SDS-insoluble gel protein isolated from mature wheat as triangles ( $n=3 \pm$ s.d.). The gel protein from mature wheat is clearly much larger compared to the gel protein isolated from protein bodies.
$55 \mathrm{kDa}$ ), several other proteins were present. It is possible that the triticin observed in the present study was either covalently bound to the SDS-soluble gluten polymers or was itself present in a range of polymeric forms. However, it was clearly not present in the SDSinsoluble gel fraction. This is in agreement with the results obtained by CLSM (Fig. 5B), as Bechtel et al. (1991) showed that triticin was present in inclusion bodies which were similar in appearance to those that were dissolved by treatment with SDS in the present study.

\subsection{Particle size}

It has been shown that GMP isolated from mature flour consists of spherical glutenin particles (Don et al., 2003). Despite the similarity in the subunit compositions of the PB and GMP fractions, the particles present in the GMP fraction from mature wheat were significantly larger (241-fold) than those in the SDS-insoluble fraction from PBs (average diameter of $76 \pm 2 \mu \mathrm{m}$ compared with $12.3 \pm 0.2 \mu \mathrm{m}$ ). Furthermore, the mean volume of the particles present in the SDS-insoluble fraction from PBs $\left(0.972 \times 10^{-9} \mathrm{ml}\right)$ is similar to that of the protein bodies themselves $\left(0.839 \times 10^{-9} \mathrm{ml}\right)$ : the fact that the PBs are $14 \%$ smaller may be explained by swelling of the protein in the presence of SDS.

The average volume of the inner starchy endosperm cells is $0.994 \times 10^{-6} \mathrm{ml}$ per cell whereas the average volume of the peripheral (subaleurone) cells is $0.217 \times 10^{-6} \mathrm{ml}$ per cell (Evers, 1970; Kent and Jones, 1952). All wheat endosperm cells also contain approximately the same weight of protein (Evers, 1970) with the differences in volume relating to variation in starch content. In particular, the subaleurone cells are densely packed with protein compared with the central cells which contain mainly starch. If we assume that a glutenin particle with an average diameter of $76.49 \mu \mathrm{m}$ is a perfect sphere then it would have an average volume of $0.234 \times 10^{-6} \mathrm{ml}$, which is equivalent to the average volume of a subaleurone cell at the end of the desiccation phase. In addition, the SDS-insoluble GMP fraction of mature wheat also contains fractions of smaller sizes than the main peak. Hence, it is possible that some of the GMP particles correspond to the matrix proteins 
present in single subaleurone cells and others to smaller deposits in the central endosperm cells.

\subsection{From protein body to glutenin particle}

It has been suggested that a glutenin particle could result from the swelling of a single protein body (Don, 2005b). The results presented in this paper show that a 241 -fold increase in volume would be required, which is in agreement with the calculations of Don (2005b). Furthermore, we observed that PBs from immature wheat can form a physical gel in SDS solution which also consists of particles of similar size (with only a $14 \%$ increase in volume) to the original protein body. This suggests a different mechanism for the formation of GMP than simple swelling of a protein body, with the GMP particles originating from the fused protein body matrix present in mature cells rather than individual PBs in developing cells.

Although the accumulation of polymeric protein is a continuous process starting as early as 7 days after flowering (DAF), a close correlation was found between the accumulation of the GMP and the rapid loss of water, which occurs during the late stages of grain development (Carceller and Aussenac, 1999, 2001). During this stage the percentage of SDS-insoluble polymers as a proportion of total polymers can increase from $10 \%$ to $50 \%$, whereas the synthesis of protein had already stopped at the end of the kernel ripening (Carceller and Aussenac, 1999). The fusion of ER-derived PBs with protein storage vacuoles has already occurred before the desiccation phase and it is possible to observe ER-derived PBs inside the vacuole and surrounded by one or two membranes in addition to the vacuolar membrane (Galili, 1997). Therefore, the absorption of PBs into protein storage vacuoles alone cannot explain the rapid increase in SDS-insoluble protein during the desiccation phase and a second mechanism must operate during the desiccation phase. Carceller and Aussenac (2001) showed that premature desiccation of the grain induces SDS-insoluble polymer formation while Rhazi et al. (2003) suggested that glutathione may play a role in controlling the degree of polymerisation.

Another mechanism which may be relevant to the formation of GMP is the loss of membrane integrity due to programmed cell death at the end of seed development. Young and Gallie (1999) demonstrated the loss of membrane integrity using Evans Blue staining of wheat endosperm cells during seed development, which increased from 20 DAF until the entire endosperm was stained at 30 DAF. The loss of membrane integrity therefore could be associated with the desiccation phase and the formation of GMP which could make the free $\mathrm{SH}$ groups present in the protein bodies and protein storage vacuoles accessible for aggregation and cross linking.

Our results therefore support the proposed relationship between $\mathrm{PBs}$ and glutenin particles, but suggest that further aggregation of individual $\mathrm{PBs}$ is required to generate the large particles observed in GMP.

\section{Acknowledgements}

This research was partially funded by the Celiac Disease Consortium and the Netherlands Proteomics Centre, both an Innovative Cluster of the Netherlands Genomics Initiative and partially funded by the Dutch Government (BSIK03009). This research was partially funded by the Allergy Consortium Wageningen (ACW) and the Top Institute Food and Nutrition Wageningen (TIFN).

\section{Appendix A. Supplementary data}

Supplementary data associated with this article can be found, in the online version, at doi:10.1016/j.jcs.2008.07.002.

\section{References}

Bechtel, D.B., Wilson, J.D., Shewry, P.R., 1991. Immunocytochemical localization of the wheat storage protein triticin in developing endosperm tissue. Cereal Chemistry 68, 573-577.

Carceller, J.L., Aussenac, T., 1999. Accumulation and changes in molecular size distribution of polymeric proteins in developing grains of hexaploid wheats: role of the desiccation phase. Australian Journal of Plant Physiology 26, 301-310.

Carceller, J.L., Aussenac, T., 2001. Size characterisation of glutenin polymers by HPSEC-MALLS. Journal of Cereal Science 33, 131-142.

Dachkevitch, T., Autran, J.C., 1989. Prediction of baking quality of bread wheats in breeding programs by size-exclusion high-performance liquid chromatography. Cereal Chemistry 66, 448-456.

Davy, A., Blom, M.S., Svendsen, I., Cameron-Mills, V., Simpson, D.J., 2000. Prediction of protein cleavage sites by the barley cysteine endoproteases EP-A and EP-B based on the kinetics of synthetic peptide hydrolysis. Plant Physiology 122, 137-146.

Don, C., 2005. General discussion. In: Don, C. (Ed.), Factors Affecting the Hyperaggregation of Glutenin Particles. Thesis, Wageningen University, pp. 183-204 (Chapter 8).

Don, C., Lichtendonk, W.J., Plijter, J.J., Hamer, R.J., 2003a. Glutenin macropolymer: a gel formed by particles. Journal of Cereal Science 37, 1-7.

Don, C., Lichtendonk, W.J., Plijter, J.J., Hamer, R.J., 2003b. Understanding the link between GMP and dough: from glutenin particles in flour towards developed dough. Journal of Cereal Science 38, 157-165.

Don, C., Lookhart, G., Naeem, H., MacRitchie, F., Hamer, R.J., 2005a. Heat stress and genotype affect the glutenin particles of the glutenin macropolymer-gel fraction. Journal of Cereal Science 42, 69-80.

Don, C., Lichtendonk, W.J., Plijter, J.J., van Vliet, T., Hamer, R.J., 2005b. The effect of mixing on glutenin particle properties: aggregation factors that affect gluten function in dough. Journal of Cereal Science 41, 69-83.

Evers, A.D., 1970. Development of the endosperm of wheat (Triticum aestivum L.). Annals of Botany 34, 547-555.

Galili, G., 1997. The prolamin storage proteins of wheat and its relatives. In: Larkins, B.A., Vasil, I.K. (Eds.), Cellular and Molecular Biology of Plant Seed Development. Kluwer Academic Publishers, The Netherlands, pp 221-256.

Graveland, A. 1984. In: Graveland, A., Moonen, J.H.E. (Eds.), Proceedings of the 2nd International Gluten Workshop on Gluten Proteins. Pudoc, Wageningen pp. 59-67.

Graveland, A., Bosveld, P., Lichtendonk, W.J., Moonen, J.H.E., 1982. Extraction and fractionation of wheat flour proteins. Journal of the Science of Food and Agriculture 33, 1117-1128.

Kent, N.L., Jones, C.R., 1952. The cellular structure of wheat flour. Cereal Chemistry 29, 383-398.

Kim, W.T., Franceschi, V.R., Krishman, H.B., Okita, T.W., 1988. Formation of wheat protein bodies: involvement of the Golgi apparatus in gliadin transport. Planta $176,173-182$.

Köhler, P., Belitz, H.D., Wieser, H., 1993. Disulphide bonds in wheat gluten: further cystine peptides from high molecular weight (HMW) and low molecular weight (LMW) subunits of glutenin and from $\gamma$-gliadins. Zeitschrift für Lebensmittel Untersuchung und -Forschung 196, 239-247.

Millar, S.J., 2003. The development of near infrared (NIR) spectroscopy calibrations for the prediction for wheat and flour quality. Project report no. 310, Home Grown Cereals Authority, London.

Morel, M.H., Dehlon, P., Autran, J.C., Leygue, J.P., Bar-L'Helgouac'h, C., 2000 Effects of temperature, sonication time, power settings on size distribution and extractability of total wheat flour proteins as determined by sizeexclusion high-performance liquid chromatography. Cereal Chemistry 77, 685-691.

Parker, M.L., 1980. Protein body inclusions in developing wheat endosperm. Annals of Botany 46, 29-36.

Rabilloud, T., Carpentier, G., Tarroux, P., 1988. Improvement and simplification of low-background silver staining of proteins by using sodium dithionite. Electrophoresis 6, 288-291.

Rhazi, L., Cazalis, R., Lemelin, E., Aussenac, T., 2003. Changes in the glutathione thiol-disulfide status during wheat grain development. Plant Physiology and Biochemistry 41, 895-902.

Rubin, R., Levanony, H., Galili, G., 1992. Characterization of two types of protein bodies in developing wheat endosperm. Plant Physiology 99, 718724.

Shevchenko, A., Wilm, M., Vorm, O., Mann, M., 1996. Mass spectrometric sequencing of proteins from silver-stained polyacrylamide gels. Analytical Chemistry 68, 850-858.

Shewry, P.R., 1999. The synthesis, processing, and deposition of gluten proteins in the developing grain. Cereal Foods World 44, 587-589.

Shewry, P.R., Halford, N.G., 2002. Cereal seed storage proteins: structures, properties and role in grain utilization. Journal of Experimental Botany 53, 947-958.

Singh, N.K., Shepherd, K.W., 1985. The structure and genetic control of a new class of disulphide-linked proteins in wheat endosperm. Theoretical and Applied Genetics 71, 79-92.

Singh, N.K., Shepherd, K.W., 1987. Solubility behaviour, synthesis, degradation and subcellular location of a new class of disulphide-linked proteins in wheat endosperm. Australian Journal of Plant Physiology 14, 245-252. 
Singh, N.K., Shepherd, K.W., Langridge, P., Gruen, L.C., 1991. Purification and biochemical characterization of triticin, a legumin-like protein in wheat endosperm. Journal of Cereal Science 13, 207-219.

Singh, N.K., Donovan, G.R., Carpenter, H.C., Skerritt, J.H., Langridge, P., 1993. Isolation and characterization of wheat triticin cDNA revealing a unique lysine-rich repetitive domain. Plant Molecular Biology 22, 227-237.

Sievert, D., Sapirstein, H.D., Bushuk, W., 1991. Changes in electrophoretic patterns of acetic acid-insoluble wheat flour proteins during dough mixing. Journal of Cereal Science 14, 243-256.

Wang, M., van Vliet, T., Hamer, R.J., 2005. Interaction of water unextractable solids and xylanase with gluten protein: effect of wheat cultivar. Journal of Cereal Science 41, 251-258.

Weegels, P.L., van de Pijpekamp, A.M., Graveland, A., Hamer, R.J., Schofield, J.D., 1996. Depolymerisation and repolymerisation of wheat gluten during dough processing 1. Relationships between GMP content and quality parameters. Journal of Cereal Science 23, 103-111.

Weegels, P.L., Hamer, R.J., Schofield, J.D., 1997. Depolymerisation and re-polymerisation of wheat glutenin during dough processing. II. Changes in composition. Journal of Cereal Science 25, 155-163.

Wellner, $\mathrm{N}$, Mills, E.N., Brownsey, G. Wilson, R.H., Brown, N., Freeman, J. Halford, N.G., Shewry, P.R., Belton, P.S., 2005. Changes in protein secondary structure during gluten deformation studied by dynamic Fourier transform infrared spectroscopy. Biomacromolecules 6, 255-261.

Wieser, H., 2007. Chemistry of gluten proteins. Food Microbiology 24, 115119.

Young, T.E., Gallie, G.R., 1999. Analysis of programmed cell death in wheat endosperm reveals differences in endosperm development between cereals. Plant Molecular Biology 39, 915-926. 